\title{
Taylor, the Disability Disclosure Virtual Assistant: A Case Study of Participatory Research with Disabled Students
}

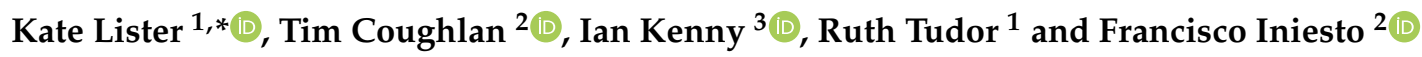 \\ 1 Faculty of Wellbeing, Education and Language Studies, The Open University, Milton Keynes MK7 6AA, UK; \\ ruth.tudor@open.ac.uk \\ 2 Institute of Educational Technology, The Open University, Milton Keynes MK7 6AA, UK; \\ tim.coughlan@open.ac.uk (T.C.); francisco.iniesto@open.ac.uk (F.I.) \\ 3 Faculty of Science, Technology, Engineering and Mathematics, The Open University, \\ Milton Keynes MK7 6AA, UK; ian.kenny@open.ac.uk \\ * Correspondence: kate.lister@open.ac.uk
}

\section{check for}

updates

Citation: Lister, K.; Coughlan, T.; Kenny, I.; Tudor, R.; Iniesto, F. Taylor, the Disability Disclosure Virtual Assistant: A Case Study of Participatory Research with Disabled Students. Educ. Sci. 2021, 11, 587. https://doi.org/10.3390/ educsci11100587

\section{Academic Editors:}

Estefanía Martín-Barroso, David Roldán Álvarez and Debra Costley

Received: 27 August 2021

Accepted: 24 September 2021

Published: 27 September 2021

Publisher's Note: MDPI stays neutra with regard to jurisdictional claims in published maps and institutional affiliations.

Copyright: (c) 2021 by the authors. Licensee MDPI, Basel, Switzerland. This article is an open access article distributed under the terms and conditions of the Creative Commons Attribution (CC BY) license (https:/ / creativecommons.org/licenses/by/ $4.0 /)$.

\begin{abstract}
Administrative burden in education is a serious issue for disabled students. Form-filling and bureaucracy are ubiquitous in further and higher education, particularly for students who need to disclose a disability and arrange for accommodations and support for an equitable educational experience. Paradoxically, many of these processes are inherently inaccessible for disabled students, and yet completing them can be critical to their success. Artificial Intelligence has potential to alleviate some of the burden imposed by administration and bureaucracy; virtual assistants and chatbots can replace forms with dialogue, without placing additional strain on institutions. However, it is essential that solutions are designed in partnership with disabled students to ensure that students ${ }^{\prime}$ needs are met, their concerns addressed, and the final solution is equitable for them. This paper explores a case study of participatory research with disabled students in a large UK distance learning institution, in which participatory research identified an issue of administrative burden for disabled students, and a virtual assistant was designed as a solution using participatory design. It shares the methodology and design process, explores findings from different phases of the research, and shares recurrent themes arising throughout the study. In doing so, it aims to provide a foundation for future participatory research to reduce barriers for disabled students.
\end{abstract}

Keywords: disability; accessibility; administrative burden; bureaucracy; artificial intelligence; participatory research; partnership

\section{Introduction}

It is a truth almost universally acknowledged that students with disabilities are systemically and systematically disadvantaged in higher education [1-4]. Studies have identified a wide range of barriers for disabled students in areas ranging from the built environments of universities [5,6], the expected use of technologies and lack of effective support [7], difficulties with course activities or content [8], discipline-specific challenges [3], and the use of language and terminology in disability disclosure and support processes that conflicts with how disabled students prefer to represent themselves $[9,10]$. These difficulties and disadvantages impact on disabled student success, as evidenced by persistent differences in degree outcomes for disabled students [11].

There are moral and legal imperatives for institutions to address these issues. The social model of disability [12] places the responsibility on universities as the creators of these barriers through the decisions they make. However, these barriers can be deeply entrenched in systems and cultures; there is often no clear or straightforward solution. For example, debates around the language used to describe disability have led institutions to adopt either 'person first' or 'identity first' language models, both of which may alienate students $[9,13]$. There is a need for educators, designers and researchers to work with their 
students, and demonstrate ongoing, 'persistent intent' [14] to improve equity in higher education. However, instead of embodying a social model approach, institutional systems, processes and cultures too often represent an inherently medical model of disability, where individuals are seen as responsible for the problems they face, and must do the work to seek help and remedy these [15].

Administrative burden, emerging from inaccessible, stressful, and time-consuming bureaucratic processes, is an important example of a complex barrier, which leads to systemic disadvantage for disabled students [16]. Form-filling and administrative processes are ubiquitous throughout further and higher education; they can dominate one of the first interactions students have with an institution, and this means that the disadvantage they represent to certain students begins right at the beginning of their educational experience. Processes are frequently onerous for disabled students, both due to their design and the effect of the student's disability $[16,17]$. Forms may ask questions that are difficult for students to answer, such as asking them to imagine and summarize the impacts of their disability on their studies before they have actually started to study (and, as such, are not in a position to know.) The medical model nature [15] of many administrative processes may have a negative impact on students' sense of identity and self-worth, by asking them to list vulnerabilities, deficits or difficulties, instead of focusing on strengths and abilities [9]. The written nature of forms can be a challenge for students with disabilities that affect their reading and writing, such as dyslexia, while the pressure of needs assessment interviews can be triggering for neurodiverse students, or students with mental health difficulties such as anxiety [17]. Many forms require students to select what 'type' of disability they have, often according to a governmental or institutional list of categories, and this can make it problematic for students to 'fit' themselves into specific categories. This, in turn, adds to the anxiety of filling in the form and may be a disincentive to disclosing a disability and seeking support at all [9]. This is increasingly a concern in higher education, with calls for action from sector bodies to streamline administrative processes and address the issues caused by administrative burden [18].

Artificial intelligence may offer possibilities to alleviate administrative burden $[19,20]$ and support education more broadly [21]. Conversational user interfaces (CUIs) such as chatbots and virtual assistants can offer a dialogic approach that has the potential to introduce more diverse methods to communicate and collect administrative data. However, accessibility considerations in the design and implementation of virtual assistants are underexplored [17], and AI solutions are often not designed to be inclusive. To ensure diverse users' needs are considered, and that virtual assistants present an equitable, accessible option to alleviate administrative burden, a participatory approach is advisory, working in partnership with users with a range of disabilities.

Participation is a key principle in disability studies, often summarized as 'nothing about us without us' [22]. There is a recognized need to take action to reduce the historical 'culture of silence', in which silence has been imposed on marginalized groups as a form of oppression [23]. Research on the 'sociology of absences' [24] has identified ways in which silences are actively created through marginalization or suppression of voices, the ways in which struggles and knowledges are not permitted to be voiced, and the impact these absences have had on human rights for marginalized groups [24]. These silences may not be deliberate; Seale highlights different ways in which disabled voices may be mediated in research and calls for meaningful participation for disabled people in educational and technological research [25].

However, truly inclusive participatory research can be challenging and time-consuming to complete $[26,27]$. The literature relating to participatory research in education highlights the complexities of meaningfully engaging disabled participants, and the tensions between participants' skills, interests and level of comfort taking part in research [28]. There is a need for researchers to consider whether their participants will be involved throughout the project, including research design, analysis, and dissemination of findings [26]. They should also consider their own positionality; whether they identify as a member of the dis- 
abled community, and the extent to which the research is participatory or emancipatory [29], i.e., whether it seeks to listen and understand participants, or whether it aims to empower and amplify their voices [30].

Participation is also key when designing solutions to issues and ensuring that technologies that pervade peoples' lives are built with some direction, input and understanding from their perspectives. Computer science and design literature emphasizes the importance of the 'Scandinavian values' in participatory design, which include 'striving for democracy and democratization; explicit discussions of values in design and imagined futures; and ways that conflicts and contradictions are regarded as resources in design' [31]. There are different degrees and models of involvement; for example, user-centered design approaches are widely used, seeking to understand users' needs and gather feedback, but still consider them the subject of the research. In contrast to this, Participatory Design (PD) aims to give the potential users of a system a more active role in the design process, in recognition of their expertise and influence, positioning users as partners across different stages in the design process, from the initial conception through to evaluation and dissemination [32].

Co-design draws on the tradition and values of participatory design [33], where participant engagement is crucial to ensure that the end product meets the needs of participants, and will be accepted and adopted by them. Participatory design principles are embodied in co-design practices as end-user involvement and cooperation, ensuring the output of participatory design is user-centered [34]. Co-design enables the integration of different types of knowledge in ways that ensure global knowledge is reconsidered in ways that meet the needs of the local context. Following these principles, co-design helps to facilitate organizational change; being typically organized around events as sites of exploration, experimentation, and transformation. Co-design events, if purposefully planned and facilitated, are aimed at creating something new, employing adjusted techniques to gather and create new knowledge [35].

This paper explores a case study of participatory research and design with disabled students in the Open University, a large UK distance learning institution. In this example, participatory research and inquiry identified an issue of administrative burden for disabled students, and a virtual assistant was designed as a solution using a participatory design approach. This paper shares the participatory methodology and design process explores findings from different phases of the research, shares recurrent themes arising throughout the study and presents the virtual assistant created. In doing so, it demonstrates 'persistent intent' to reduce a systemic barrier to equality [14] and aims to provide a foundation for future participatory research to reduce barriers for disabled students in higher education.

\section{Materials and Methods}

This study took place in the Open University (OU), a four-nation distance learning university in the UK, with over 33,000 students disclosing disabilities. OU study is modular; degree programs are composed of modules worth 30-60 CATS points (15-30 ECTS credits) that typically last one academic year. Study takes predominantly online or via blended learning, with a number of live (usually online) tutorials taking place throughout the module. Students are assessed through coursework and an end of module assessment, such as an exam, extended essay, or other task. All OU materials are designed to be accessible, and reasonable adjustments are arranged for students with disabilities, including provision of alternative formats of course materials. Students may disclose disabilities at any point in their studies, and have access to educational advice and support from general and specialist student support teams. The OU has offices and student support teams in all four UK nations; England, Scotland, Wales and Northern Ireland.

This paper documents an ongoing, 'persistent intent' [14] project, enacted over three phases. The research was approved by the Open University's Student Research Project Panel and Human Research Ethics Committee (The ethical approval number is HREC/3712.). As this study took place in the UK, this paper adopts a predominantly 
'identity first' model of language, referring to 'disabled students' rather than 'students with disabilities', as is the UK norm [10].

\subsection{Phase 1: Creating a Student-Driven Research Agenda}

Phase 1 followed a participatory inquiry approach, seeking to 'allow people to voice opinions on issues that directly affect their lives' [36]. It aimed to explore barriers and difficulties disabled students experience in higher education and identify a student-driven research agenda. This took place in 2016 and was both co-designed with and co-facilitated by the OU Students Association (OUSA) Disabled Students Group (DSG).

The inquiry comprised both in-person and online activities, offering both light-touch and more in-depth engagement opportunities in each. This design decision was taken because the DSG advised that this variety of engagement options was likely to lead to a positive experience for participants, and to richer results. Also, participants in this phase of the study retained anonymity [37], so participant demographics for this phase have not been included in this paper.

The inquiry used DSG platforms to engage with students, and participants were recruited using DSG communications. Online activity took place on Facebook and on a DSG discussion forum, as these were the OUSA DSG's preferred platforms. The light-touch engagement options were a discussion thread in both spaces asking students about the things that make it hard to live and study independently, and what they would like to see changed. The more in-depth engagement option was a one-week Facebook event with themed discussions and activities on each day. This was designed to start conversation, provide scope for students to learn from each other and to encourage the social benefit of students supporting each other and providing long term benefit for fellow students in similar situations. In order to avoid immediate focus on research without developing shared context, calls to share 'Life Hacks' and 'Study Hacks' occurred in the first two days. This then moved to 'Pet Peeves' as a means to identify problems. In the final two days, themes arising from these conversations were used to prompt further discussions.

In-person activity took place on campus during the OUSA student conference in 2016. The light-touch engagement option was a conference exhibition stand posing the same question as the online discussion, asking students what made it hard to live and study independently and what they would like to see changed. The more in-depth engagement option was a face-to-face workshop with similar activities to the online event, focusing on life hacks, pet peeves and solutions, and identifying themes for further investigation.

The data arising from this phase was textual, consisting of anonymized social media posts, notes and comments from the workshop and written comments from the exhibition stand. The data were analyzed using Thematic Analysis [38].

\subsection{Phase 2: Exploring the Issue of Administrative Burden}

Phase 2 followed a participatory research approach. It aimed to explore in more depth an issue that students raised in Phase 1; the issue of administrative burden for disabled students. First, interviews were held with five DSG members using narrative inquiry to capture their experiences. Building on this, a survey was co-designed with DSG stakeholders and sent to 1000 students with disabilities.

109 students responded to the survey, with participants representing all 12 categories of disability captured by the university [16]. The data were analyzed using descriptive statistics. The survey methodology, instrument design and more detailed description of participant demographics are available in Coughlan et al. [16].

\subsection{Phase 3: Co-Designing a Solution}

Phase 3 followed a participatory design (PD) approach. It focused on the barrier presented by disability disclosure processes, identified in Phase 2 , and aimed to co-design an AI-driven solution in the form of a virtual assistant. A variety of PD methods were used, 
and students participated throughout the project, from the initial research design through to the dissemination of outcomes at the end of the project.

Two PD workshops were held, aiming to seek broad student and staff stakeholder engagement. Workshops were held in England and Scotland; 13 students and eight staff (student support advisors) attended overall. Of the 13 students, seven were female, four were male. Mobility disabilities, long-term medical conditions, fatigue and pain conditions, sensory impairments, mental health issues and learning difficulties were represented in the participants.

Four disabled students were employed on contracts throughout the design process, and three other students took part in specific tasks and were compensated with vouchers. Of the seven student participants, three were female and four were male; mobility disabilities, sensory impairments, mental health issues and learning difficulties were represented.

Students were engaged in user-centered evaluation, via a beta trial and main trial. The details of the beta trial are published in Iniesto et al. [39].

The results from all three phases of the research are presented in the next section.

\section{Results}

\subsection{Findings from Phase 1: Student-Driven Research Agenda}

In the initial particiaptory inquiry, a range of themes pertaining to a research agenda were identified and collated from the online discussions and workshop. Several of these themes led to the identification of administrative burden as an issue and a priority in the reseacrh agenda. These themes were explained by students as:

- Disability disclosure, including fear of telling people about hidden issues.

- Access to information, disabled students not knowing or understanding their rights.

- Understanding the varied sources of help available to students and working to improve those.

- Barriers created by restricted channels of communication, such as written forms or phone calls. Exploring how alternatives should be provided.

- More flexible assistance, such as non-medical helper support for study that did not need formal arrangements.

- Greater flexibility in deadlines and course schedules to support study at different rates.

- Inaccessibility of assessments, lack of effective adjustments made in relation to assessments, and problems in organising reasonable adjustments.

Further themes in the discussion beyond this area included the need for better access to social and leisure services, and challenging the assumptions about disability by making the diversity more visible beyond physical disabilities,

The discussions led to a research agenda with ten ideas for projects. The project ideas linking to the administrative burden theme were:

- Measuring and researching the amount of time disabled people spend on processes like declaring a disability, applying for Disabled Students Allowance, the UK government Personal Independence Payments, and others. How does this affect their studies or well-being? Could data on this burden be used to address the inequities found in study?

- Investigating the ways in which organisational processes require people to use a particular communication channel (e.g., only allowing certain actions by phone, email or in-person) and what impact this has on disabled people.

- Investigating how study support interventions, such as mentors, or peer support groups, can improve disabled students' study experiences.

- Interrogating the elements that make study flexible and understanding how these benefit disabled students.

- Investigating the extent to which the social model of disability is understood and accepted, and what the barriers are to it having a greater impact. 
- Exploring how disabled people feel about the language used to describe disability, particularly in disclosure processes, and what language they use themselves when they interact with different people or situations.

From the point of view of the researchers, these themes and project ideas were valuable outcomes that would not have been achieved without direct engagement with the members of the DSG and students association. This agenda prompted several projects relating to different themes, all of which were known to be grounded in the needs raised by the community. The problems identified by the participants were subsequently more widely recognised [18] but were new inspirations to us at the time.

\subsection{Findings from Phase 2: Administrative Burden}

Phase 2 aimed to explore in more depth the issue of administrative burden, and the themes relating to this that students had raised in Phase 1. Narrative inquiry interviews with five disabled students revealed a range of issues, barriers and impacts that students had experienced. These are given below, with student quotes to illustrate the issues. Inaccessibility of forms

'The really annoying thing is I can't fill the forms in myself because Dolphin and Dragon, when used together, don't work with the forms, especially the boxes in the forms. You can't click on the bit you're supposed to click on. That means I have to pay my carer $£ 11.50$ an hour to do it for me. And it's not just the money, it's actually really embarrassing having to tell a stranger things about yourself and your disability so they can fill in the forms.'

Confusing processes

'When you're new, or you don't know the ropes or what it is you're supposed to do, it's horrible, it's very confusing and stressful. It's like everyone knows the system and it's working against you, but you don't know how to work it and you're fumbling in the dark.'

Unclear timescales

'After the assessment, they don't tell you how long you have to wait until you find out what you've been awarded. There's no time limit. It's awful, as your course start date gets nearer and nearer you get more and more agitated about it.'

Impact on disabilities

'Stress affects my condition and makes it worse, so I'm finding that as I'm getting more agitated, my condition's getting worse, too, and it's affecting my daily life'

Feeling powerless

'And all the time you're waiting you're thinking about it. How will this affect my life. Everything you've got, everything you do, you're thinking how much longer will I have this for? What happens if I have to live without it? How will I manage, how will I cope? It's like you're an insect under a magnifying glass. You've got no power'

Impact on studies

'My PIP letter came through on the day on my exam. I have my exam at home, and I was writing the exam and I heard the letterbox go and saw the brown envelope. I couldn't stop thinking about it. I couldn't focus on the exam. I was thinking, everything is there, my whole future is in that envelope. I had to ask my invigilator to put it where I couldn't see it'

Financial impact

'Every year I waste time and money filling in details on forms, the same details the $\mathrm{OU}$ have already got, such as my name and address and information about my disability. I'm paraplegic, it's not going to change! Then I have to pay for a doctor's letter to prove it, too, which is more money and hassle.'

Ongoing processes 
'One form leads to another, they're like dominoes, once you start and you push one, they just all knock onto each other and they all go flat. Each form leads to another form, each process leads to another process... I still need to fill in the forms every year, even though I'm not entitled to anything anymore. I'm not allowed to stop. Actually, I should do more.

\section{Avoidance of processes}

My condition's changed, I've been diagnosed with something else, but I'm not telling the university because I just don't want to go through the hassle of a reassessment.'

Building on this qualitative data, a survey was co-designed with students that would seek quantitative data to further explore adminsitrative burden. This survey aimed to investigate which administrative processes were most challenging for disabled students, and the impacts the processes had on a wider number of students. The survey findings are described in detail in Coughlan et al. [16], but revealed a range of negative impacts that administrative processes had had on students (see Table 1). The impacts experienced by most students included stress, mental health and increased negative impressions of the institutions carrying out the administrative processes [16].

Table 1. Extent of impact of administrative processes on nine identified dimensions of impact $(n=104)$.

\begin{tabular}{|c|c|c|c|c|}
\hline Type of Impact & $\begin{array}{c}\text { Positive/Very Positive } \\
\text { Effect }\end{array}$ & No Effect & $\begin{array}{l}\text { Negative/Very } \\
\text { Negative Effect }\end{array}$ & N/A \\
\hline Effect on time spent on studies & $14.4 \%$ & $47.1 \%$ & $37.5 \%$ & $1.0 \%$ \\
\hline Quality of your coursework assignments & $15.4 \%$ & $51.9 \%$ & $25.9 \%$ & $6.7 \%$ \\
\hline Ability to succeed in exams & $14.4 \%$ & $34.6 \%$ & $17.4 \%$ & $33.7 \%$ \\
\hline Mental health & $7.7 \%$ & $40.4 \%$ & $45.2 \%$ & $6.7 \%$ \\
\hline Physical health or wellbeing & $6.7 \%$ & $46.2 \%$ & $37.5 \%$ & $9.6 \%$ \\
\hline Stress levels & $5.7 \%$ & $29.8 \%$ & $61.5 \%$ & $2.9 \%$ \\
\hline Effect on your disabilities & $9.6 \%$ & $41.3 \%$ & $41.3 \%$ & $7.7 \%$ \\
\hline $\begin{array}{l}\text { Effect of dealing with OU processes on } \\
\text { impression of the university }\end{array}$ & $42.3 \%$ & $26.0 \%$ & $27.9 \%$ & $3.8 \%$ \\
\hline $\begin{array}{l}\text { Effect of dealing with council or government } \\
\text { processes on impression of those departments }\end{array}$ & $6.7 \%$ & $18.3 \%$ & $50.9 \%$ & $24.0 \%$ \\
\hline
\end{tabular}

The survey also revealed that disability-related processes were generally considered more challenging than general or everyday administrative processes. Of the processes related to students' university experiences, the disability disclosure process was felt to be most challenging (see Table 2) [16].

Table 2. Degree of challenge perceived in types of process $(n=109)$.

\begin{tabular}{|c|c|c|c|c|}
\hline Question & $\begin{array}{l}\text { Challenging or Very } \\
\text { Challenging }\end{array}$ & $\begin{array}{l}\text { No Strong } \\
\text { Opinion }\end{array}$ & $\begin{array}{l}\text { Straightforward or } \\
\text { Very Straightforward }\end{array}$ & N/A \\
\hline $\begin{array}{l}\text { Administrative processes necessary in everyday life } \\
\text { (such as paying bills or banking) }\end{array}$ & $24.8 \%$ & $17.4 \%$ & $52.3 \%$ & $5.5 \%$ \\
\hline $\begin{array}{l}\text { General processes at the Open University (such as } \\
\text { registering for a module or updating your address) }\end{array}$ & $18.4 \%$ & $12.8 \%$ & $68.8 \%$ & $0.0 \%$ \\
\hline $\begin{array}{l}\text { Disability-related processes at the Open University } \\
\text { (such as declaring a disability or asking for an } \\
\text { adjustment to be made) }\end{array}$ & $33.9 \%$ & $19.3 \%$ & $42.2 \%$ & $4.6 \%$ \\
\hline Disability-related processes outside of the Open & & & & \\
\hline $\begin{array}{l}\text { University (such as applying for PIP, or a blue } \\
\text { parking badge) }\end{array}$ & $48.6 \%$ & $11.9 \%$ & $12.9 \%$ & $26.6 \%$ \\
\hline $\begin{array}{l}\text { Administrative processes where you need to } \\
\text { communicate with both the OU and with other } \\
\text { organisations in order to complete them (such as } \\
\text { applying for DSA) }\end{array}$ & $45.0 \%$ & $16.5 \%$ & $18.3 \%$ & $20.2 \%$ \\
\hline
\end{tabular}


The finding that the disability disclosure process was the most challenging universityowned administrative process was particularly valuable to the research team, as this meant that this process was an ideal testbed to design and pilot a potential solution.

\subsection{Findings from Phase 3: Co-Designing a Solution}

Upon consultation with staff and student stakeholders, it was decided that a virtual assistant could represent a possible solution. There were several potential benefits to such an assistant; first, a conversational approach had potential to alleviate the confusion caused by processes or question wording; second, giving students choice between forms and an assistant could reduce the sense of powerlessness students reported; and third, careful technical design of the assistant could reduce accessibility issues students encountered with forms.

Early in the design process, two participatory design workshops were held with students and staff to seek broad input into themes that could inform the assistant design. Stakeholder input can be broadly categorised into six themes:

- Accessibility

- Appearance and personality

- Conversation design

- Bi-directional dialogue

- Human support

- Transparency

These themes are explored in more detail below. Example artefacts from the workshops illustrating some of these themes are shown in Figure 1.

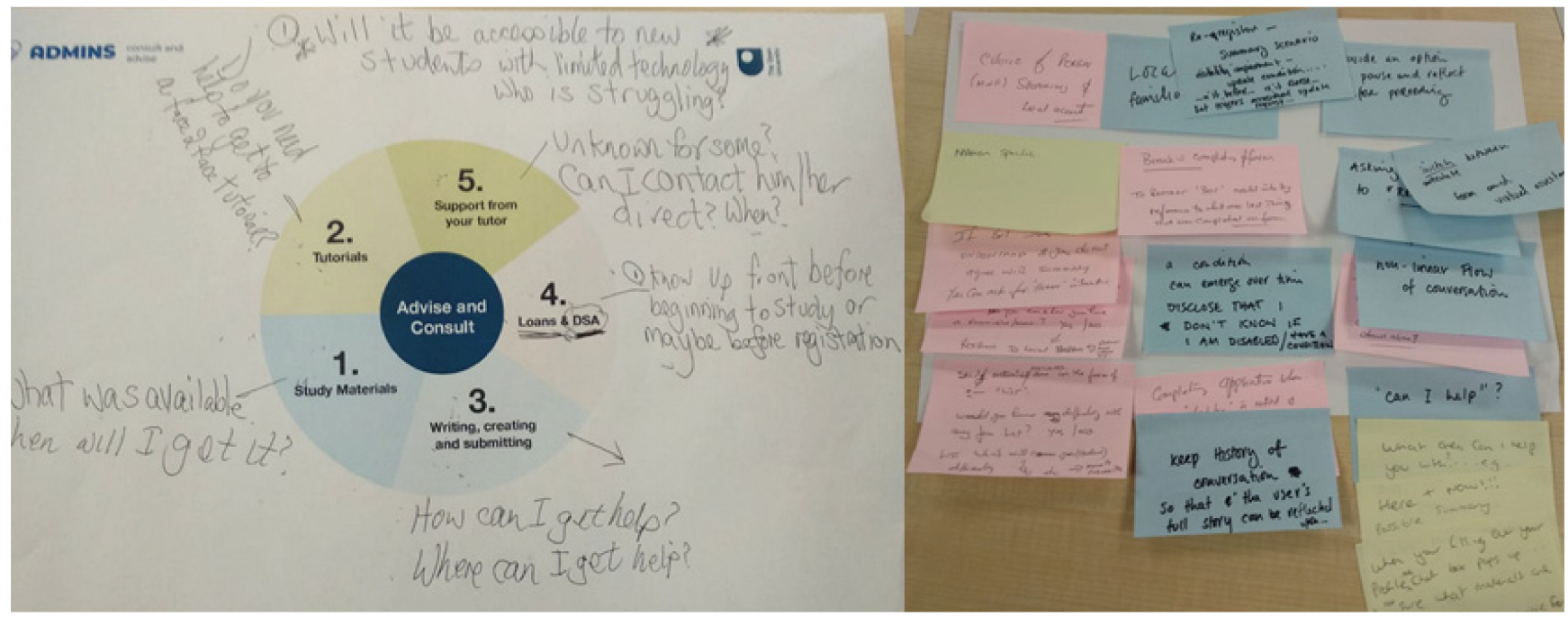

Figure 1. Artefacts from completed workshop activity.

Accessibility

Technical accessibility was unsurprisingly of paramount importance to students, and they highlighted the importance of flexibility as part of this. In addition to working with all types of assistive technology, students stated that an assistant must be accessible on smartphones, tablets and computers, and across diffferent operating systems. They also stated they wanted to choose between spoken and written interaction with an assistant, either through speech-to-text or text-to-speech assistive technology, or through the bot design.

Appearance and personality

In terms of appearance, students felt that an assistant should be gender-neutral, or that students should have a choice of gender when engaging with an assistant. They felt the assistant's appearance should be representative of the OU, incorporating the branding and logo. It should not be 'too cartoony'. 
Students expressed that the assistant's personality should be friendly, supportive, empathetic and calm, asking questions like 'How can I help you?' or 'What do you need?' It should be professional and polite, asking permission to address students by their first name, and should not be 'chatty.' It should have a clear voice, ideally a human voice rather than a synthesised voice, possibly with a regional dialect or choice of dialects.

Conversation design

Students expressed that they did not like the way the questions were framed in the original disability disclosure form; they felt that an assistant should frame questions in a different way, and that it should be an alternative to the form that gathered information through dialogue, rather than an assistant that sat alongside the form and 'helped' students if they had questions. For example, certain parts of the form are in the form of a list or tickboxes, such as students being asked to tick which disability category they belonged to; students stated that they did not like this approach and they preferred instead open questions, such as 'Tell us about your disability.'

Students expressed concern about the potential pace of conversation, saying that they wanted 'an option to pause and reflect' at times before proceeding with the conversation. They also expressed a preference for flexibility in the flow of conversation, asking whether the conversation would need to be completed in a particular order or whether sections could be completed independently or in a different order.

Bi-directional dialogue

In addition to an assistant asking them questions, students expressed a desire to be able to ask the assistant questions in return, for it to provide information to them as part of a bi-directional dialogue. They stated that new students, in particular, do not understand how the OU works; they may not know what a tutorial is, how the interaction with the tutor works or what support is available to them, and they therefore do not know how to fill in parts of the form. They felt that the assistant should provide relevant information; for example, videos to illustrate situations described in the form, and definitions of certain aspects of OU study, such as tutorials or alternative formats. They wanted students to be able to ask open questions, such as 'Can you tell me what study materials are on offer?' or 'Am I eligible for Disabled Students Allowance?', or seek help through statements such as 'I don't know if I am disabled.' As well as providing basic information, they wanted the assistant to signpost students to further information, i.e., providing links, like a 'help centre of information'.

Human support

Students felt that there should be human support available in the event of miscommunication with an assistant. For example, if the assistant did not understand them, or if they didn't agree with its statements, they should have the option to quickly and easily make contact with a person, i.e., a human advisor, who could resolve the issue. They also felt that there should be flexibility and choice in the manner of communication with the person; that some students may prefer to communicate by email while others would prefer to talk with an advisor on the phone.

Transparency:

Students felt strongly that an assistant should not 'pretend to be human'; it should be clear from the outset that it was a bot.

Students also wanted to be able to see a summary of what the assistant had understood from them; a history of the conversation so that their 'full story' could be reflected upon. They said they wanted this at the end of the conversation, in addition to a clear message of the next steps that would be taken following the conversation, and agreement of the communication channels by which any further communication would take place (e.g., phone, email, etc.) They also said an assistant should check that students consent to the sharing of their information with tutors and other OU staff.

Following the workshops, students were employed on consultancy contracts throughout the development stage of the project, in which the assistant (named Taylor, see Figure 2) was developed. Student consultants played an active role in championing the considera- 
tions raised in the PD workshops, they iteratively tested the assistant, and led on particular aspects of design or development of their choosing. This led to several critical incidences, or points of coalescence, in which student consultants made decisions that influenced the design of the assistant. These related to four of the themes identified in the workshops:

- Accessibility

- Appearance and personality

- Conversation design

- Transparency

These incidences are described below.

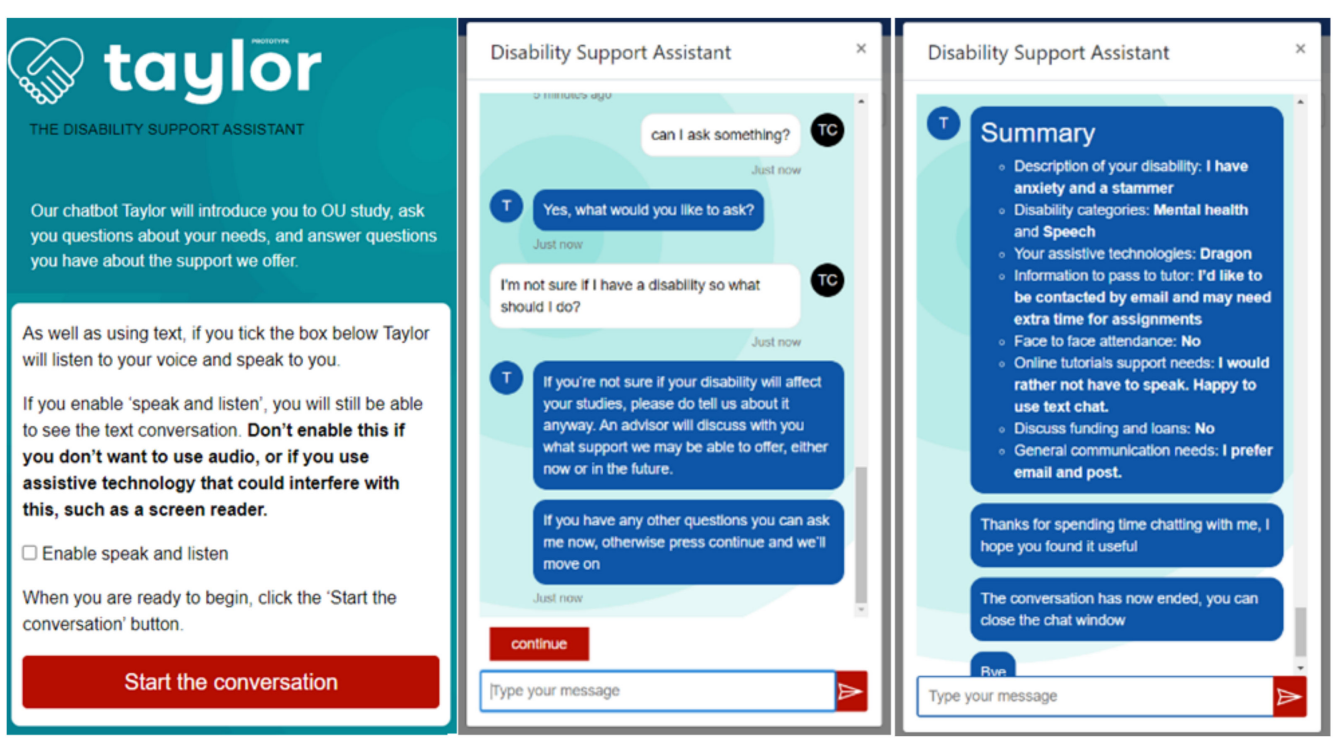

Figure 2. Taylor, the disability disclosure assistant.

Accessibility

Student consultants identified a key accessibility concern in the speed of the assistant's speech; some students found it too fast while others found it too slow. This led to flexibility and choice forming a key part of the assistant's design, as the onboarding conversation flow was subsequently designed to ask students whether they would like to change the speed at which Taylor was speaking, thus giving them choice over the speed of interaction.

Appearance and personality

Student consultants played a crucial role in the assistant's appearance and personality. They chose its name, Taylor, for its gender neutral qualities and association with 'tailored' disability support. They voted on its design, and commented extensively on its dialogue and phrasing. They also chose its voice from a wide range of available voices; one student consultant with a hearing impairment tested the voices for intelligibility, and the others contributed to the final decision.

Conversation design

There was discussion in the PD workshops about the format of questions, particularly in relation to the disability disclosure question. The students in the PD workshops expressed a desire for an open question instead of a tickbox; the student consultants championed this throughout the design process and contributed to the design of the open question and subsequent intelligent classification of disability in Taylor's conversation flow.

Transparency

Students in the PD workshops expressed a desire to see a summary at the end of the conversation with the assistant. The student consultants built on this, identifying and championing the need for students to be able to request a summary at any time at any point in the conversation. This functionality was built into Taylor's design, thus enabling greater transparency for students. 
Prior to the main trial, the assistant was tested in a participatory beta trial with staff and students. The beta trial provided rich feedback, catalysing reflection within the team aligned with the themes identified to implement accessible virtual asssistants. These themes included management of user expectations and clear limitations of what Taylor can achieve; allowing personalisation, and ensuring empathy with the use of the language and the way information is presented. The beta trial is reported in more detail in Iniesto et al. [39]. The main trial will be explored in a subsequent publication.

\section{Discussion}

The literature is clear that when engaging in meaningful participatory research, care should be taken to ensure that people with disabilities are genuinely consulted and included in the process of developing and delivering the solutions from which it is intended that they will benefit $[40,41]$. This was invaluable in this study; by including our participants, we were able to identify and explore a problem (administrative burden) and create a solution that was not driven by technology, but by the needs of disabled students as a heterogeneous group.

The participatory approach adopted throughout the phases of this study led to the identification of a number of recurring themes. One critical theme was the multiple different issues inherent in disability disclosure processes; not only the administrative burden created by them, but also issues relating to the processes, language, and types of questions involved in the process. Students in Phase 1 described the fear of telling people about hidden issues, and identified a project relating to the language used in disability disclosure processes. Wider literature in the area also supports these concerns; the design of disability disclosure has been shown to be critical in encouraging students to disclose $[1,42,43]$, and language is a crucial part of that $[9,10,44,45]$. In Phase 2 , students talked about the financial burden of obtaining evidence and related avoidance of the disclosure process, ranking disability disclosure the most challenging process in the university [16]. In Phase 3 , students critiqued the way disclosure questions can be framed as a list of tickboxes, stating a preference for an open question. Again, literature supports this; critiquing closed questions as 'unhelpful' [42] and advocating for more discursive, conversational approaches [10,42]. In this study, in partnership with students, we have been able to move beyond the static open questions in forms to a more truly conversational approach, which was received positively by students in the beta trial [46]. This was primarily due to the meaningful and ongoing nature of participation with disabled students over the phases of the project, as many of these issues would not have arisen sufficiently if the participation was limited to discretized, one-off workshops, or consultations.

Another theme in the study was the relationship between accessibility and flexibility. In Phase 1, students talked about inaccessibility and lack of flexibility as separate themes. They critiqued inaccessibility of assessments, particularly in terms of lack of reasonable adjustments, and called for greater flexibility in deadlines and more flexibility in non-medical assistance. Their perceptions are supported by literature critiquing lack of accessibility and inclusion in higher education assessment $[1,8,47]$, and lack of flexibility in student support is a perennial theme in the literature [25,48,49]. In Phase 2, students discussed the technical inaccessibility of forms, revealing diverse perceptions of accessibility, and the impacts inaccessibility had on them. Flexibility was not explicitly mentioned in Phase 2, but became of paramount importance in Phase 3 when students were designing a solution. They highlighted the importance of the assistant being accessible and flexible, working effectively across different platforms and devices, as well as functioning with different assistive technologies, and expressed the need for flexibility and choice in the manner of interacting (i.e., through spoken and written interaction.) This was an interesting connection in the context of this study, and literature in the field also draws a clear connection between flexibility and accessibility in design [17,25,50,51].

In partnership with students, this study was able to realize both accessibility and flexibility considerations in Taylor's design. For example, Taylor was designed to communicate 
through voice or text input and output. The implementation therefore included voice recognition, voice synthesis (text-to-speech) as well as the traditional text-based format of communication, meaning we were able to avoid assumptions about how the person interacting with Taylor usually interacts with computer interfaces, and that students were able to choose their preferred style of communication at the time of use. Other examples of accessibility and flexibility realized in Taylor's design are the way students are supported to interact at their own pace, to set their speed of speech, and to ask questions at any time throughout Taylor's question set. These design features were inspired as a direct result of the participatory design process, and they attempt to reduce the sense of powerlessness in relation to administrative processes that students described in Phase 2.

A third recurrent theme related to the clarity and transparency of administrative processes, and students' understanding of what was available. In Phase 1, students raised the issue of lack of understanding of what support is available to them, and in Phase 2 they expanded on this, discussing confusing administrative processes and unclear timescales. They reported that these barriers left them feeling powerless, and led to increases in their stress levels which could impact their disabilities. Literature in the field supports this; Read et al. discuss the sense of disempowerment disabled people experience when reasonable adjustment processes are not clear or consistent [52], and Holloway identifies the stress and anxiety disabled students can experience when information about their courses is not clear [53]. In Phase 3, this theme arose in terms of students requesting clarity in conversation design, and transparency of the assistant's role, purpose, processes and next steps. In partnership with students, this was realised in Taylor's design; student consultants iteratively tested the conversation flow for clarity in dialogue, and held the development team to account when it came to making changes to diaglogue. They also worked with the team to ensure that Taylor was transparent about its role (i.e., that it was a bot and not human) and about the next steps and timescales in the disclosure process following the conversation (i.e., that an advisor would contact the student within ten days.) Furthermore, upon request from the students, a design feature was implemented that ensured students could request a full summary of the conversation at any time in the process, aiming to mitigate the sense of powerlessness students described in Phase 2.

Participatory design involves a level of compromise [54,55]; not all of the students ideas were implemented in practice. For example, Taylor has a synthetic (although lifelike) voice rather than a human one, and students are not given a choice of voices with different genders or regional accents. Technical and system constraints meant that students are not given the option to transfer seamlessly to a human being in the event of miscommunication, and only one illustrative video was included in Taylor's final design. However, the participatory approach and close partnership with disabled student consultants ensured that design decisions were made in an inclusive way, balancing individual preferences with the needs of a broader group of students, as well as university requirements and technical constraints. Furthermore, some of the students' ideas represent ideas for future research and development directions, including the consideration of greater personalization and flexibility in the assistant design, and potential to include more personalized suggestions for support.

\section{Conclusions}

This paper has explored a case study of participatory research and design with disabled students. It has recounted how participatory inquiry identified an issue of administrative burden for disabled students, participatory research sought qualitative and quantitative data to further explore this, and a participatory design project created a virtual assistant as a solution to the issue. This combination of participatory inquiry, research and design has played an important role in identifying and potentially reducing a systematic disadvantage for disabled students in our educational context, and we propose that the method could be beneficial in other contexts. The findings themselves, in terms of the 
themes that arose throughout the study, also hold potential benefit in other contexts, to help institutions identify barriers and design solutions.

There were a number of challenges and limitations in this study. As is common with participatory research, the number of students taking part was small, and it is likely they did not adequately represent the complexity and diversity of experiences, needs and preferences that exist within the disabled student population. Furthermore, the selfselecting nature of participant recruitment means that certain groups of students will not have had a voice in the different phases of the study; for example, the use of an online survey in Phase 2 may have acted as a barrier for students who struggle with online surveys (even though the survey tool was accessibility compliant.) Additionally, Phase 3 of the study took place from October 2019 to January 2021, so although the two PD workshops took place in-person, the majority of development and interaction with the student consultants took place in the context of the global pandemic. This meant that online workarounds had to be found for design interactions (such as sprint meetings) that had been planned to take place in-person. The pivot to online engagement affected the design process both positively and negatively; one student consultant was not able to attend face-to-face meetings due to complex disabilities, so the fact that everyone was online made his experience more equitable. However, another student relied on lip-reading, and found online meetings to be challenging. It is impossible to know how this altered engagement is reflected in Taylor's final design, but the rush to find suitable online alternatives to face-to-face interaction in the early months of the pandemic certainly added a layer of complexity to the participatory design process.

This paper has shared the value gained from the participatory approach adopted in this study, has explored findings from different phases of the research, and discussed recurrent themes raised throughout the study. In doing so, it has demonstrated the results of persistent intent to resolve a problem for disabled students, and has aimed to provide a positive example of participatory research, aiming to increase equity and reduce barriers for disabled students in higher education.

Author Contributions: Conceptualization, methodology, investigation and writing, were carried out by all authors. All authors have read and agreed to the published version of the manuscript.

Funding: Phase 3 of this research was funded by Microsoft's AI for Accessibility programme. Phases 1 and 2 received no external funding.

Acknowledgments: The authors would like to thank all the students and staff involved throughout this research.

Conflicts of Interest: The authors declare no conflict of interest.

\section{References}

1. Healey, M.; Bradley, A.; Hall, T. Barriers to learning: A systematic study of the experience of disabled students in one university. Stud. High. Educ. 2004, 29, 303-318. [CrossRef]

2. Vickerman, P.; Blundell, M. Hearing the voices of disabled students in higher education. Disabil. Soc. 2010, 25, 21-32. [CrossRef]

3. Pearson, V.; Lister, K.; McPherson, E.; Gallen, A.-M.; Davies, G.; Colwell, C.; Bradshaw, K.; Braithwaite, N.; Collins, T. Embedding and Sustaining Inclusive Practice to Support Disabled Students in Online and Blended Learning. J. Interact. Media Educ. 2019, 2019, 4. [CrossRef]

4. Lister, K.; Pearson, V.K.; Collins, T.D.; Davies, G.J. Evaluating inclusion in distance learning: A survey of university staff attitudes, practices and training needs. Innov. Eur. J. Soc. Sci. Res. 2020, 33, 1-19. [CrossRef]

5. Muzemil, A. Campus Physical Environment Accessibility for Person with Disabilities in the Ethiopian Public Universities. Int. J. Multicult. Multireligious Underst. 2018, 5, 286-302. [CrossRef]

6. Low, J. Negotiating Identities, Negotiating Environments: An interpretation of the experiences of students with disabilities. Disabil. Soc. 1996, 11, 235-248. [CrossRef]

7. Seale, J.; Georgeson, J.; Mamas, C.; Swain, J. Not the right kind of 'digital capital'? An examination of the complex relationship between disabled students, their technologies and higher education institutions. Comput. Educ. 2015, 82, 118-128. [CrossRef]

8. Fichten, C.S.; Ferraro, V.; Asuncion, J.V.; Chwojka, C.; Barile, M.; Nguyen, M.N.; Klomp, R.; Wolforth, J. Disabilities and e-Learning Problems and Solutions: An Exploratory Study. J. Educ. Technol. Soc. 2009, 12, 241-256. 
9. Lister, K.; Coughlan, T.; Owen, N. Learning Needs, Barriers, Differences and Study Requirements: How Students Identify as "disabled" in Higher Education. Widening Particip. Lifelong Learn. 2000, 22, 95-111. [CrossRef]

10. Lister, K.; Coughlan, T.; Owen, N. Disability' or "Additional study needs"? Identifying students' language preferences in disability-related communications. Eur. J. Spec. Needs Educ. 2020, 35, 620-635. [CrossRef]

11. Hubble, S.; Paul, B. Support for Disabled Students in Higher Education in England. Paper 8716. House of Commons Briefing: Westminster, UK, 2021. Available online: https://dera.ioe.ac.uk/37466/1/CBP-8716\%20\%282\%29\%20\%28redacted\%29.pdf (accessed on 23 September 2021).

12. Oliver, M. Social Work with Disabled People; Macmillans: Basingstoke, UK, 1983.

13. Lister, K.; McPherson, E.; Coughlan, T.; Gallen, A.-M.; Pearson, V. Towards Inclusive Language: Exploring Student-Led Approaches to Talking about Disability-Related Study Needs. In Proceedings of the 12th annual International Conference of Education, Research and Innovation (ICERI 2019), Seville, Spain, 11-13 November 2019; Volume 12, pp. 1444-1453. Available online: http:/ / oro.open.ac.uk/68408/ (accessed on 12 July 2020).

14. Coughlan, T.; Lister, K.; Seale, J.; Scanlon, E.; Weller, M. Accessible Inclusive Learning: Foundations; Ubiquity Press, Ltd.: Berkeley, CA, USA, 2019; pp. 51-73. [CrossRef]

15. Retief, M.; Letšosa, R. Models of disability: A brief overview. HTS Teol. Stud. Theol. Stud. 2018, 74, 8. [CrossRef]

16. Coughlan, T.; Lister, K. The accessibility of administrative processes: Assessing the impacts on students in higher education. In Proceedings of the 15th International Cross-Disciplinary Conference on Web Accessibility (Web4All 2018), New York, NY, USA 23-25 April 2018. Available online: https: / / www.dropbox.com/sh/e2dz1y41fzrxsks / AADd5ZVDoPiGbCFHHgV7IusWa?dl=0\& preview=21.pdf (accessed on 11 August 2020).

17. Lister, K.; Coughlan, T.; Iniesto, F.; Freear, N.; Devine, P. Accessible conversational user interfaces. In Proceedings of the 17th International Web for All Conference, Taipei, Taiwan, 20-21 April 2020; pp. 1-11. [CrossRef]

18. Hector, M. Arriving at Thriving: Learning from Disabled Students to Ensure Access for All; Policy Connect: London, UK, 2020. Available online: https://www.policyconnect.org.uk/research/arriving-thriving-learning-disabled-students-ensure-access-all (accessed on 26 July 2021).

19. Han, W.; Jun, D.; Xiaopeng, G.; Kangxu, L. Supporting quality teaching using educational data mining based on OpenEdX platform. In Proceedings of the 2017 IEEE Frontiers in Education Conference (FIE), Indianapolis, IN, USA, 18-21 October 2017; pp. 1-7. [CrossRef]

20. Embarak, O. Apply Machine Learning Algorithms to Predict At-Risk Students to Admission Period. In Proceedings of the 2020 Seventh International Conference on Information Technology Trends (ITT), Abu Dhabi, United Arab Emirates, 25-26 November 2020; pp. 190-195. [CrossRef]

21. Winkler, R.; Söllner, M. Unleashing the Potential of Chatbots in Education: A State-Of-The-Art Analysis. In Proceedings of the Academy of Management Annual Meeting (AOM), Chicago, IL, USA, 10-14 August 2018. Available online: https: //www.alexandria.unisg.ch/254848/ (accessed on 6 August 2021).

22. Charlton, J. Nothing about Us Without Us, 1st ed.; University of California Press: Berkeley, CA, USA, 1998. Available online: https:/ / www.ucpress.edu/book/9780520224810/nothing-about-us-without-us (accessed on 26 July 2020).

23. Freire, P. Cultural Action for Freedom; Penguin Books: London, UK, 1972.

24. Santos, B.D.S. Nuestra America. Theory Cult. Soc. 2001, 18, 185-217. [CrossRef]

25. Seale, J.K. E-Learning and Disability in Higher Education: Accessibility Research and Practice, 2nd ed.; Routledge: New York, NY, USA, 2014. Available online: https://www.routledge.com/products/9780415629416 (accessed on 24 April 2020).

26. Jackson, S.F. A Participatory Group Process to Analyze Qualitative Data. Prog. Community Health Partnersh. Res. Educ. Action 2008, 2, 161-170. [CrossRef] [PubMed]

27. Schneider, B. Participatory Action Research, Mental Health Service User Research, and the Hearing (our) Voices Projects. Int. J. Qual. Methods 2012, 11, 152-165. [CrossRef]

28. Rix, J.; Garcia-Carrizosa, H.; Hayhoe, S.; Seale, J.; Sheehy, K. Emergent analysis and dissemination within participatory research. Int. J. Res. Method Educ. 2020, 44, 287-302. [CrossRef]

29. French, S.; Swain, J. Changing Disability Research: Participating and Emancipatory Research with Disabled People. Physiother. 1997, 83, 26-32. [CrossRef]

30. Chappell, A.L. Emergence of participatory methodology in learning difficulty research: Understanding the context. Br. J. Learn. Disabil. 2000, 28, 38-43. [CrossRef]

31. Gregory, J. Scandinavian Approaches to Participatory Design. IJEE 2003, 19, 62-74.

32. Sanders, E.B.-N.; Stappers, P.J. Co-creation and the new landscapes of design. CoDesign 2008, 4, 5-18. [CrossRef]

33. Wang, F.; Hannafin, M.J. Design-based research and technology-enhanced learning environments. Educ. Technol. Res. Dev. 2005, 53, 5-23. [CrossRef]

34. Holmlid, S. Participative, co-operative, emancipatory: From participatory design to service design. In Proceedings of the DeThinking Service, ReThinking Design, Oslo, Norway, 24-26 November 2009. Available online: https:/ / www.semanticscholar. org / paper/Participative\%2C-co-operative\%2C-emancipatory-\%3A-From-to-Holmlid/da718a27ef15714e6c7a26b052fb31d374 41f5e6 (accessed on 23 August 2021). 
35. Mattelmäki, T.; Visser, F.S. Lost in CO-X-Interpretations of Co-Design and Co-Creation. In Proceedings of the IASDR'11, 4th World Conference on Design Research, Delft University, Delft, The Netherlands, 31 October-4 November 2011. Available online: https:/ / research.aalto.fi/en/publications/lost-in-co-x-interpretations-of-co-design-and-co-creation (accessed on 23 August 2021).

36. Fischer, F. Technological deliberation in a democratic society: The case for participatory inquiry. Sci. Public Policy 1999, 26, 294-302. [CrossRef]

37. Wiles, R.; Crow, G.; Heath, S.; Charles, V. Anonymity and Confidentiality; National Centre for Research Methods Working Paper; December 2008. Available online: https:/ / eprints.ncrm.ac.uk/id/eprint/423/ (accessed on 18 September 2021).

38. Braun, V.; Clarke, V. Using thematic analysis in psychology. Qual. Res. Psychol. 2006, 3, 77-101. [CrossRef]

39. Iniesto, F.; Coughlan, T.; Lister, K. Implementing an accessible conversational user interface. In Proceedings of the 18th International Web for All Conference; Association for Computing Machinery (ACM): New York, NY, USA, 2021; pp. 1-5.

40. Seale, J.; Nind, M.; Parsons, S. Inclusive research in education: Contributions to method and debate. Int. J. Res. Method Educ. 2014, 37, 347-356. [CrossRef]

41. Seale, J.; Colwell, C.; Coughlan, T.; Heiman, T.; Kaspi-Tsahor, D.; Olenik-Shemesh, D. ‘Dreaming in colour': Disabled higher education students' perspectives on improving design practices that would enable them to benefit from their use of technologies. Educ. Inf. Technol. 2021, 26, 1687-1719. [CrossRef]

42. Rose, C. Do you Have a Disability — Yes or No? Or Is There a Better Way of Asking? Guidance on Disability Disclosure and Respecting Confidentiality; Learning and Skills Development Agency: London, UK, 2006. Available online: https:// files.eric.ed.gov/fulltext/ ED508509.pdf (accessed on 23 September 2021).

43. Riddell, S.; Weedon, E. Disabled students in higher education: Discourses of disability and the negotiation of identity. Int. J. Educ. Res. 2014, 63, 38-46. [CrossRef]

44. Kenny, L.; Hattersley, C.; Molins, B.; Buckley, C.; Povey, C.; Pellicano, E. Which terms should be used to describe autism? Perspectives from the UK autism community. Autism 2016, 20, 442-462. [CrossRef] [PubMed]

45. Rosenblum, L.P.; Erin, J.N. Perceptions of Terms Used to Describe Individuals with Visual Impairments. Review 1998, 30, 15-26.

46. Iniesto, F.; Coughlan, T.; Lister, K.; Holmes, W. Designing an Assistant for the Disclosure and Management of Information about Needs and Support: The ADMINS project. In Proceedings of the 22nd International ACM SIGACCESS Conference on Computers and Accessibility, New York, NY, USA, 26-28 October 2020; pp. 1-4.

47. Lopez-Gavira, R.; Moriña, A.; Morgado, B. Challenges to inclusive education at the university: The perspective of students and disability support service staff. Innov. Eur. J. Soc. Sci. Res. 2019, 1-13. [CrossRef]

48. Beilke, J.R.; Yssel, N. The Chilly Climate for Students with Disabilities in Higher Education. Coll. Stud. J. 1999, $33,364$.

49. Botham, K.; Nicholson, J. Supporting the transition of disabled students from university to practice placement. Disabil. Soc. 2014, 29, 460-476. [CrossRef]

50. Yesilada, Y.; Harper, S. Web Accessibility: A Foundation for Research, 2nd ed.; Yesilada, Y., Harper, S., Eds.; Springer: London, UK, 2019.

51. Erlandson, R.F. Universal and Accessible Design for Products, Services, and Processes; CRC Press: Boca Raton, FL, USA, 2007.

52. Read, S.; Heslop, P.; Turner, S.; Mason-Angelow, V.; Tilbury, N.; Miles, C.; Hatton, C. Disabled people's experiences of accessing reasonable adjustments in hospitals: A qualitative study. BMC Health Serv. Res. 2018, 18, 931. [CrossRef] [PubMed]

53. Holloway, S. The Experience of Higher Education from the Perspective of Disabled Students. Disabil. Soc. 2001, 16, 597-615. [CrossRef]

54. Benke, I.; Knierim, M.T.; Maedche, A. Chatbot-based Emotion Management for Distributed Teams. Proc. ACM Hum. Comput. Interact. 2020, 4, 1-30. [CrossRef]

55. Luck, R. Participatory design in architectural practice: Changing practices in future making in uncertain times. Des. Stud. 2018, 59, 139-157. [CrossRef] 